\title{
Ensino de História da África e Cultura Afro-brasileira: Desafios e Possibilidades
}

\author{
Denise Maria de Souza Bispo \\ Luiz Gustavo Santos da Silva
}

\section{Resumo}

A aprovação da Lei 10.639/03, depois das constantes lutas do movimento negro organizado, é um avanço na valorização da História africana e afro-brasileira no currículo oficial da rede de ensino de nosso país. Quando nos propomos a questionar sobre a necessidade real do aprendizado da História africana e cultura afro-brasileira, buscamos através de uma postura política levantar algumas possibilidades de afirmação e positivação ao contextualizar a memória coletiva africana que se faz presente nas representações do nosso cotidiano. Desta maneira, esse artigo propõe pensar caminhos e desafios para o trabalho da História da África e cultura afrobrasileira em sala de aula.

Palavras Chaves: África, diversidade, positivação.

\section{Teaching History of African and Afro-Brazilian Culture: Challenges and Opportunities}

\begin{abstract}
The approval of Law 10,639/03 after constant conflicts of the organized black movement is an advance in the valuation of African History and Afro-Brazilian in the official curriculum of the network of education of our country. When we consider questioning the real necessity of the learning of African History and culture AfroBrazilian, we search through a political position to raise some possibilities of affirmation and positivation when we take the African collective memory inserting it in a context that is present in the representations of our daily one. In this way, this article considers to think ways and challenges for the work of the History of Africa and culture Afro-Brazilian about classroom.
\end{abstract}

Key words: Africa, diversity, positivation. 
A aprovação da Lei 10.639[1] foi uma das várias conquistas que representaram de certa forma um avanço na valorização da história africana e afro-brasileira nos currículos escolares do nosso país. A lei, que passou a ser vigorada a partir de janeiro de 2003, confronta o universo dos professores brasileiros com o desafio de disseminar para a população uma gama de conhecimentos multidisciplinares sobre o mundo africano. Há nesse contexto a possibilidade de trazer à tona questões pertinentes relacionadas ao mundo afro-brasileiro diaspórico e às populações negras do país, populações essas que ainda sofrem os reflexos do processo escravista ocorrido no século XIX. A "farsa" da abolição nos faz atentar para o fato de que esta não livrou os ex-escravos e/ou afro-brasileiros da discriminação racial e do processo de exclusão social e miséria. O racismo passou então, a partir desse momento, a ser um dos determinantes do destino social, econômico, político e cultural dos afro-brasileiros.

Durante algum tempo, a busca da instrução (educação formal) foi almejada pelos negros como fator de integração sócio-econômica, logo após a abolição da escravatura. Os negros compreenderam que com a educação formal poderiam obter mobilidade vertical na sociedade brasileira. Porém, logo a militância e os intelectuais negros descobriram que a escola também era responsável pela perpetuação das desigualdades raciais, pois, elevava os valores eurocêntricos que reproduziam as desvantagens históricas e a exclusão dos negros das oportunidades a padrões naturalizados.

Percebemos evidentemente que o ensino brasileiro estabeleceu uma educação formal de embranquecimento cultural em sentido amplo. Embranquecimento cultural, nesse sentido, refere-se à hegemonia da história eurocêntrica nas escolas brasileiras em detrimento a valorização da história de outros continentes. Observando os currículos escolares, do primeiro grau à universidade - salvo raras exceções podemos observar que a presença das populações negras é restrita a poucas páginas, e ainda, em sua maioria, dedicadas à escravatura.

Ouvimos falar durante toda a nossa vida escolar dos romanos, dos gregos e de suas cidades-estado, de Napoleão, das "potências aliadas". No entanto, ao se referir à história do continente africano, que é múltiplo, heterogêneo, dedicam-se algumas poucas páginas. Isso quando se fala. $\mathrm{O}$ que não deve ficar restrito apenas à História como disciplina. E nas Letras e nas Artes? Nos currículos das universidades brasileiras poucas são as disciplinas destinadas ao estudo das literaturas ou artes africanas.

A historiografia, de certa maneira, invisibilizou a África. Segundo Waldemir Zamparoni (2006), "esta prática ilusionista não é apanágio da dita 'história tradicional' ou conservadora. Marxistas ou não, ortodoxos ou adeptos da 'História Nova' todos parecem ser modernos adeptos de Hegel: a África, afirmava o filósofo alemão, não tem interesse histórico próprio, senão o de que os homens vivem ali na barbárie e no selvagerismo, sem apontar nenhum ingrediente à civilização".

Na construção do conhecimento sobre as sociedades humanas, sabe-se que elaborar e dar sentido à história de um povo é dar a este povo instrumentos para a formação de sua própria identidade. Nesse caso, para as populações negras diaspóricas, é preciso promover a sua história de forma a despertar em todos os sujeitos sociais a auto-estima, a inserção social e a identidade étnico-cultural e política dessas populações, apresentando sua formação e contribuição histórica qualificada e seu conteúdo não folclorizado.

Assim, como nos afirma Lima (2004), "a inclusão deturpada ou exclusão deliberada de algum aspecto desta história pode implicar na criação de uma identidade ou de uma auto-imagem distinta da realidade daquele grupo humano, distorcida ou definida segundo elementos ideológicos distantes do real", uma vez que a negação desta história esteve sempre associada a formas de controle social e dominação ideológica, tratando-se sempre as populações negras como minorias e retirando sempre o conteúdo racial da construção da identidade brasileira, tudo isso amparado pelo arcabouço das teorias raciais cientificistas e pelo desejo esquizofrênico de branqueamento da sociedade.

A sanção da Lei 10.639/03 constituiu-se em um fato importante na história da legislação educacional brasileira, visto que a historiografia oficial exerceu o silêncio sobre o processo civilizatório africano no Brasil. A principal mudança estabelecida pela Lei é que 
ela tornou obrigatório o ensino sobre História e Cultura Afro-brasileira no currículo oficial da rede de ensino e incluiu como conteúdo programático:

\section{[...] o estudo sobre História da África e dos africanos, a luta dos negros no Brasil, a cultura negra brasileira e o negro na for- mação da sociedade nacional resgatando a contribuição do povo negro nas áreas soci- al, econômica e política pertinente à Histó- ria do Brasil (Texto da Lei 10.639/ 03).}

Diversos desafios são colocados diante do professor, tais como: organizar um currículo que atenda a essas necessidades no que diz respeito à escolha dos conteúdos a serem abordados, materiais didáticos a serem utilizados; analisar a capacidade reflexiva do sistema educacional brasileiro sobre esse tema, etc. Talvez um dos pontos importantes dessa discussão seja a questão relacionada à organização do currículo. Não podemos, no afã da efetivação propriamente dita da lei, "sobrecarregar" os alunos com uma gama de conteúdos sobre África e cultura afro-brasileira sem atentar para a correlação entre os assuntos e sua contextualização.

A Lei 10.639/03 pode contribuir para o amadurecimento da luta da população afro-descendente no Brasil, com as políticas de ação afirmativa, para a redução das desigualdades. As ações afirmativas emergem nesse momento como formas de positivação dos valores civilizatórios afro-brasileiros através de medidas que corroborem a sua efetivação. Para Mattos (2003, p.230) "não se trata simplesmente de contrapor de forma maniqueísta e ingênua, à memória social herdada, uma outra memória social e racial positiva e supostamente superior. Trata-se, sim, de ativar a possibilidade de dar expressão e significado a conteúdos históricos concretos silenciados pelas memórias dominantes, trazer à cena e positivar os conteúdos não codificados pelas linguagens convencionais, ressignificar as sociabilidades não-hegemônicas e as múltiplas temporalidades do viver cotidiano".

\section{A lei 10.639/03 na sala de aula: possibilidades de construção da positivação dos valores civilizatórios afro-brasileiros}

Quando propomos questionar a necessidade real do aprendizado da história africana e cultura afrobrasileira, estamos buscando, através de uma postura política, levantar algumas possibilidades ao contextualizar a memória coletiva que se faz presente nos mitos, nas cantigas, na religiosidade, nos aspectos corporais, gestuais, emblemáticos, cosmogônicos, expressados na origem e ancestralidade da matriz cultural em África.

A tradição oral é, para as sociedades africanas, a identificação da atmosfera político-econômico-social que valida a ligação entre o homem e a palavra. A oralidade africana é definida como testemunho transmitido de uma geração a outra que tem no verbalismo a sua maneira de concepção geral do mundo para entender a visão e o significado profundo da temporalidade e da estrutura mental que compreendem as representações coletivas, constituindo formas e expressões do cotidiano. Construir uma pedagogia que possa contemplar a pluriculturalidade brasileira é criar e possibilitar um encontro a partir de si próprio, dos próprios referenciais identitários brasileiros. Porém, o papel do professor é determinante no processo de auto-reconhecimento, reapropriação e reinvenção do aprendizado.

Perpetua-se a insistência numa imagem didaticamente elaborada, em que a população afro-brasileira é abordada sempre como incapaz de civilização, incapaz de promover sua própria libertação e, sobretudo, de ser agente histórico, realizador e capaz de estabelecer sua própria forma de existência. Neste sentido, acreditamos na ação imediata do educador que, nesse contexto, é peça fundamental para descaracterizar os discursos ideológicos construídos ao longo dos séculos.

Existem formas e alternativas de se trabalhar com valores perpassados na História da cultura africana diaspórica, com base na identificação da cultura negra produzida no Brasil por africanos e seus descen- 
dentes, correlacionando sua ancestralidade (arkhê) a formas de vida dos afro-brasileiros enraizados em nosso cotidiano. Segundo Léa Austrelina apud Luz, "a noção de arkhé é utilizada para projetar a compreensão da episteme africana e da linguagem que a sustenta. A arkhé caracteriza-se por princípios inaugurais que dão propulsão ao existir. É uma elaboração de passado que dá significado à existência, imprime sentido e direção ao futuro. No seio da arkhé estão contidos os princípios de começo-origem e podercomando, e não deve ser associada com antiguidade e/ou anterioridade e exemplo de um passado rural, não-tecnológico e mesmo selvagem”. [2]

A convivência comunitária, a troca, a solidariedade, a promoção da identidade negra, o respeito com os mais velhos (princípio tão importante na cultura africana - respeito à ancestralidade) são possibilidades sustentadoras de uma educação pluricultural assentada no compromisso de combater a discriminação e o racismo na educação brasileira.

A possibilidade de trabalhar o apogeu dos impérios africanos, das rotas comerciais transaarianas e a circulação dos povos estrangeiros no continente, beneficia a desmistificação das considerações que atestam a falta de organização política, econômica, social e filosófica antes da chegada dos colonizadores. É de extrema importância discutir os conhecimentos relacionados à vida na África e as possibilidades de perceber as riquezas materiais e imateriais que fazem parte do "mosaico" social africano, desde suas organizações em aldeias, cidades, reinos e impérios, oferecendo assim aos alunos a oportunidade de desconstruir concepções de inferioridade legadas às populações africanas. Atentar para os estereótipos relacionados aos laços mentais que vinculam o continente à miséria $\mathrm{e}$ à selvageria, pois, como afirma Cunha (2006, p. 02), “o elemento básico para introdução da história africana não está na história africana e sim na desconstrução e eliminação de alguns elementos básicos da ideologia racista brasileira".

O ensino de história da África deve ser visto como uma possibilidade de romper com as estruturas eurocêntricas dos nossos currículos escolares, dando aos nossos alunos oportunidades de entender que outros continentes e povos, além do europeu, contribuíram para a construção da história, estrada do passado que apresenta as conseqüências do futuro da humanidade; na afirmação de Oliva (2006, p. 424) "a história da África e a história do Brasil estão mais próximas do que alguns gostariam [...]. Devemos conhecer a África para não apenas dar notícias aos nossos alunos, mas internalizá-la neles [...]" de forma positivada.

Assim, infinitas são as possibilidades, os caminhos para o trabalho com a História da África na sala de aula, mas, cabe ao educador a seleção, a identificação e a sensibilidade com os conteúdos propostos pelas disciplinas. Os educadores devem ficar atentos quanto à seleção do conteúdo, pois a África deve ser vislumbrada antes da colonização, com seus impérios, suas organizações sociais, e logo após, a África diaspórica.

Reconhecer e valorizar as contribuições africanas, desde a antiguidade ao período contemporâneo, utilizando diferentes recursos metodológicos (filmes, mapas, textos, jogos, brincadeiras, a oralidade marca das tradições africanas), pode contribuir para a efetiva positivação da História da África e da Cultura afrobrasileira, ao quebrar a estrutura racista introjetadas na maioria dos currículos escolares, sendo esse o caminho mais seguro para compreender e conviver com as diferenças e promover a cidadania. 


\section{REFERÊNCIAS}

BEZERRA, Holien G. Ensino de História: Conteúdos e conceitos básicos. In: KARNAL, Leandro. (Org). História na sala de aula: conceitos, práticas e propostas. São Paulo. Contexto, p. 37-48, 2003.

CUNHA, Henrique. O Ensino da História Africana. Disponível em <http:// www.historianet.com.br>. Acesso em: 02 de out. 2006

. A inclusão da História africana no Tempo dos Parâmetros Curriculares Nacionais. Disponível em < http://www.mulheresnegras.org.br $>$. Acesso em: 02 de out. 2006

FONSECA, Selva Guimarães. "Incorporação de diferentes fontes e linguagens no ensino de história”. In: Didática e prática de ensino de História: experiências, reflexões e aprendizado. Campinas, SP: Papirus, 2003.

LIMA, Mônica. "Fazendo soar os tambores: o ensino de História da África e dos africanos no Brasil". In: Cadernos Pedagógicos PENESB, n. 4, p. 65-77. Niterói: Editora da UFF, 2004.

MATTOS, Wilson Roberto de. "Valores Civilizatórios Afro-Brasileiros, Políticas Educacionais e Currículos Escolares". Revista da FAEEBA. Salvador, v.1, n 19, p.229-234, jan./jun. 2003.

OLIVA, Anderson Ribeiro. A História da África nos bancos escolares: representações e imprecisões na literatura didática. Estudos Afro-Asiáticos, ano 25, n 03, p. 421-461. Disponível em < http:// www.scielo.br/pdf/eaa/v25n3/a03v25n3.pdf> . Acesso em: 26 de out. 2006.

PANTOJA, Selma. A. "África Imaginada e a África Real”. In: ROCHA, Maria José. PANTOJA, Selma. (Org.). Rompendo Silêncios: História da África nos Currículos da educação Básica. Brasília, v. 1, p. 21$23,2004$.

WEDERSON, Carlos Moore. "Novas bases para o ensino de História da África no Brasil (considerações preliminares)". In: Educação anti-racista: caminhos abertos pela Lei Federal 10.639/03. Secretaria de Educação Continuada, alfabetização e Diversidade-Brasília: Ministério da Educação, 2005.

ZAMPARONI, Valdemir. Os Estudos africanos no Brasil: Veredas. Disponível em < http:// www.mulheresnegras.org.br>. Acesso em 10 de set. 2006.

\section{NOTAS}

1. A lei 10.639 , de 09 de janeiro de 2003 , altera a lei 9.394, de 20 de dezembro de 1996, que estabelece as diretrizes e bases da educação nacional e inclui no currículo oficial da rede de ensino a obrigatoriedade da temática História e Cultura Afro-Brasileira.

2. ATAÍDE, Yara Dulce B. MORAIS, Edimilson de Sena. A (Re) Construção da Identidade Étnica Afrodescendente a partir de uma Proposta Alternativa de Educação Pluricultural. In: Revista da FAEEBA Educação e Contemporaneidade, Salvador, v.1, n.19, p. 81- 98, jan. / jun., 2003.

\section{Sobre autores:}

Denise Maria de Souza Bispo é graduada em História pela Universidade Estadual da Bahia - UNEB Campus V, colaboradora do Grupo de discussão étnico-raciais Nyanga, aluna do curso de Especialização em História Cultural na Universidade Federal de Sergipe - UFS. E-mail: denisebispo@yahoo.com.br

Luiz Gustavo Santos da Silva é graduado em História pela Universidade Estadual da Bahia - UNEB Campus V, colaborador do Grupo de discussão étnico-raciais Nyanga e aluno especial do Mestrado em Educação na Universidade Estadual da Bahia - UNEB. E-mail: okeonire@yahoo.com.br. 
